A list of Working Papers on the last pages

No. 206,1988

FINANCIAL MARKET IMPERFECTIONS

AND PRODUCTIVITY GROWTH

by

Bruce C. Greenwald and Joseph E. Stiglitz

Paper prepared for the IUI Conference on Market for Innovation, Ownership and Control June 12-16, 1988, at Grand Hotel, Saltsjöbaden

Feb., 1989 


\title{
Financial Market Imperfections and \\ Productivity Growth
}

\author{
Bruce C. Greenwald \\ Bellcore \\ Morristown, NJ
}

\author{
and \\ Joseph E. Stiglitz \\ Stanford University \\ Stanford, CA
}

\begin{abstract}
This paper examines the impact of financial market imperfections on long-term productivity growth. It focuses on failures in markets for the sale of equity securities and hence on the failure of markets which help firms diversify the risks of real investment. The paper examines separately situations in which productivity growth is driven by learning-by-doing and where it results from the cumulative impact of explicit investments in technology by firms. In general, a multiplicity of steady-state growth paths exists with different growth rates along each path. The particular path followed by any single economy (and hence the growth rate of that economy) wili đepend significantly on policy interventions which mitigare effects of financial markets.
\end{abstract}




\section{Introduction}

This paper investigates the impact of financial markets on long run technological development. The classical approach to such a question centered on the role of financial markets in determining the level of interest rates and the impact of interest rates on investments of all kinds, including investments in research and development. With perfectly informed and competitive financial markets, interest rates are determined by the interaction of real household savings decisions and firm investment decisions. Thus, in the strictest classical (and new classical) tradition, financial markets play no role in determining the rate of technological development except in so far as they influence transactions costs in transferring funds from lender households to investor firms. However, international and interfirm differences in productivity growth which appear to be related to differences in institutional financial structures raise doubts about this simple classical description of the problem. Moreover, real financial markets appear to differ substantially from the neoclassical norm, being characterized by a wide range of informational imperfections. ${ }^{1}$

This paper, therefore, concentrates on the impact of informational imperfections markets on investment in productivity improvements. As a typical example, it examines the consequences of a situation in which the owner/managers of firms are better informed about their firms' future prospects than participants in financial markets at large. Under these circumstances, as demonstrated by Leland and Pyle [1976], Stiglitz [1982], Myers and Majluf [1984] and Greenwald, Stiglitz and Weiss [1984], markets for the sale of equity shares in firms will function only imperfectly and firms will be constrained in the amounts of equity capital that they can raise. Since

\footnotetext{
1 See Greenwald and Stiglitz [1986].
} 
these results are familiar, the focus of the paper is on how such finance constraints are likely to affect productivity growth. Consequently no attempt will be made to describe explicitly the informational underpinings of the failure of equity markets. Instead, with the aim of simplifying the analysis as far as possible, we will assume that firms are unable to raise equity in external financial markets. ${ }^{2}$

We also assume that owner/managers of firms are averse to bankruptcy, that production decisions entail risks (e.g. because inputs must be paid for before output prices are known) and that these risks cannot be eliminated by trading in futures market (e.g. because, for informational and transactions cost reasons, futures markets are incomplete). The failures in equity markets limit the abilities of firms to diversify the risks of their operations and hence lead to the reduction in the level of such operations as an alternative means of risk management. Since the curtailment of firm operations will limit the extent of on-the-job training and other learning effects as well as direct investment in productivity improvements, the capital market imperfections to which we referred earlier will adversely affect the overall rate of productivity growth.

This model, in addition, to providing a possible explanation for differences in the rate of productivity growth actoss economies also provides possible explanations for three widely observed empirical phenomena. First, it accounts for the apparent absence of decreasing returns in the process of growth (if anything higher levels of development appear to be associated with higher rather than lower rates of growth ${ }^{3}$ ). Second, our model produces firm growth rates which, consistent with Gibrat's law, are independent of firm size. Finally, the model yields the widely observed cyclical fluctuations in productivity of the kind originally noted by Okun.

\footnotetext{
2 We could equivalently assume that there are fixed, but positive, equity issue constraints. In practice, firms appear to rely to a very limited extent on external equity markets (see Taggart [1983]) and doing so appears to be costly (see Asquith and Mullins [1983]).

${ }^{3}$ See, for example, the historical data in Romer [1986].
} 
The paper consists, beyond this introduction, of three parts. Section one describes the behavior of firms and their supply decisions. Section two then embeds these firms in a general equilibrium model in which productivity growth is determined by aggregate learning-by-doing (similar to the specification used by Romer [1988]) and examines the properties of the resulting growth rates. Section three is a brief conclusion.

\section{Firm Behavior and Aggregate Supply}

\section{Outline of the theory of the Firm}

In this section, we present a simple model of the behavior of a risk- (or more precisely, bankruptcy-) averse firm, facing uncertain relative prices of the goods which it produces. The firm begins each period with an inherited net worth, or what we refer to as its equity. ${ }^{4}$ Workers ${ }^{5}$ are paid at the beginning of the period of production. If wage payments exceed the firm's

\footnotetext{
${ }^{4}$ The term "equity" has several related but distinct meanings. The term is often used to describe the market value of the firm's shares. This market value should be closely related to the use of the term here, but empirical results suggesting the " $q$ " may deviate substantially from unity imply that, at any moment, the market value of the equity may differ substantially from the firm's "net worth." In the present model, the managers of the firm are assumed to pay no attention to the stock market valuation. This is obviously an extreme assumption, but one which, we suspect, fits the facts better than the altemative polar assumption usually employed, that firm behavior is determined by the current market value of $q$. Since this number is highly volatile, the current market value of $q$ may only be loosely related to the future market value at the time an investment project is completed. This is particularly true, given the asymmetries of information between the firm's managers and outsiders. Is it likely that the firm's managers would base their business judgments more on uninformed outsider's valuation of the firm's prospects than on their own inside information? (The observed success of the " $q$ " model may be a consequence of a spurious correlation; $q$ will be high for firms that are doing well today, and these firms will also have a high "net worth." Our theory argues it is the latter, not the former, which largely determines firm behavior. Of course, to the extent that outsider's and insider's views coincide, then a firm with good investment prospects will also have a high $q$; but now it is not $q$ which is driving the firm behavior, but the underlying prospects, which are reflected in $q$.).

At the same time, $q$ is not directly relevant for the very short term concerns of the firm $-q$ does not affect the firm's bankruptcy probability, though bad prospects will be reflected again both in a low $q$ and a high bankruptcy probability. (Good prospects may also make it less likely that the firm will be subjected to credit rationing, a concem from which we abstract in this paper.)

To remind the reader of the specific way in which we use the term equity, we shall, from time to time, place the term in quotation marks.

5 In this paper, we abstract from all inputs other than labor. However, we could easily incorporate other inputs assuming that, like labor, they are paid for before output is produced.
} 
"equity" it borrows the difference. Note that the form in which capital is raised makes a difference to the behavior of the firm. Equity entails no fixed obligation. Debt entails an obligation to repay a certain amount the next period. For simplicity, we will assume all loans are for one period only. If the firm is unable to repay the loan, it goes into bankruptcy. Since all production beyond the level which the firm can finance out of its own net worth is financed by debt, as the firm produces more, its probability of bankruptcy increases. The level of production balances the gains in expected profits with the costs associated with the increased probability of bankruptcy.

In this theory, the balance sheet of the firm (its net worth) as well as the uncertainty faced by the firm (whether, in principle, diversible on the market or not) make a difference for firm behavior.

We now present the details of the model.

\section{The Model}

Firms, identified by an index $i=1, \ldots, I$, will be assumed to make decisions at discrete intervals $t=1, \ldots, T$. At the beginning of each period, a firm inherits both a nominal level of debt, $B_{t-1}^{i}$, and a "real" level of output, $q_{t-1}^{i}$, from the previous period. We will assume that there is a one-period lag between the use (and payment) of inputs and the availability of output. Thus, $q_{t-1}^{i}$ results from production decisions made at the beginning of period $t-1$, but becomes available for sale only at the beginning of period $t$. For simplicity, we will assume also that output is perishable and $q_{i-1}^{i}$ must all be sold at the beginning of period $t$. We will assume that the nominal debt, $B_{t-1}^{i}$, was incurred at the beginning of period $t-1$ in order to pay for the inputs that were required for producing $q_{t-1}^{i}$. Associated with this debt is a nominal contractual rate of interest $R_{t-1}^{i}$ determined at that time. Thus, nominal contractual repayments owed to 
debtholders by firm $i$ on entering period $t$ are $\left(1+R_{t-1}^{i}\right) B_{t-1}^{i}$.

At the beginning of period $t$ competitive goods markets for the sale of $q_{t-1}^{i}$ open and clear. This determines the price $P_{t}^{i}$ at which firm $i$ sells its inherited output, $q_{t-1}^{i}$. The price $P_{t}^{i}$ also determines the nominal "equity" position 6 of firm $i$ at the beginning of period $t$ since

$$
\begin{aligned}
A_{t}^{i} & \equiv \text { Nominal Equity Position of firm } i \text { at the beginning of period } t \\
& \equiv P_{t}^{i} q_{t-1}^{i}-\left(1+R_{t-1}^{i}\right) B_{t-1}^{i}
\end{aligned}
$$

The level of $A_{t}^{i}$ then determines the solvency of firm $i$. For some level of $A_{t}^{i}$ sufficiently low (or negative) firm $i$ would presumably be declared bankrupt and reorganized with appropriately negative consequences for the managers (or owners, if owner-managed) of the firm. For simplicity we will assume that $A_{t}^{i}<0$ implies bankruptcy, although a non-zero (either positive or negative) threshold could have been used without fundamentally altering the implications of the model. 7

Simultaneously with the clearance of the several goods markets at the beginning of period $t$, loan and labor markets open and clear. These markets determine $w_{t}$, the real wage ${ }^{8}$ that firms must offer workers, and $r_{t}$, the expected real return required by lenders. The expected real return, $r_{t}$, then determines the terms on which loans will be made available to individual firms, typically a schedule ${ }^{9}$ relating $R_{t}^{i}$ to $q_{t}^{i}$ and $A_{t}^{i}$ for a given expected real return and expected rate of inflation. Combined with expectations concerning future output prices and $A_{t}^{i}$, these factor prices lead managers to select a level of output, $q_{i}^{i}$, which, once workers have been paid, leads to

\footnotetext{
${ }^{6}$ For the moment we will ignore both equity sales and dividends.

7 It should, however, be noted that the comparative static properties of a bankruptcy threshold below zero are both more complicated and less clearly determinate than those of a zero or positive threshold.

${ }^{8}$ Given the average price level determined by the individual $P_{t}^{i}$ prices, real wage levels determine also an equilibrium nominal wage.

9 See below for detailed discussion on this point.
} 
a level of debt, $B_{l}^{i}$, and a contractual nominal retum, $R_{t}^{i}$, on that debt. Thus, this burst of simultaneous activity at the beginning of period $t$ produces levels of $q_{t}^{i}, B_{t}^{i}$ and $R_{t}^{i}$ that firm $i$ inherits at the beginning of period $t+1$, when the entire process is repeated.

Within this temporal context we will assume that

[A1] firms produce output using only labor as an input with $l_{t}^{i}=\phi\left(q_{t}^{i}\right)$ where $\phi$ is a labor requirements function ${ }^{10}$ with $\phi^{\prime}>0$ and $\phi^{\prime \prime} \geq 0 .{ }^{11}$ Firms borrow to finance all production which they cannot finance out of their "equity." Total production costs are just $P_{t} w_{t} \phi\left(q_{t}^{i}\right)$. This means that borrowings are given by

$$
B_{t}^{i}=P_{t} w_{t} \phi\left(q_{t}^{i}\right)-A_{t}^{i}
$$

[A2] the price level, $P_{t}^{i}$, faced by an individual firm is determined by a sectoral random variable, $\bar{u}_{t}^{i}$, and the overall price level, $P_{t}$, where

$$
P_{t}^{i}=\tilde{u}_{t}^{i} P_{t}, E\left(\tilde{u}_{t}^{i}\right)=1
$$

and $\bar{u}_{l}^{i}$, the relative price of the output of firm $i$, is i.i.d. with a distribution function $F(\cdot)$, and density $f(\cdot)$,

[A3] if $A_{t}^{i}<0$, firms go "bankrupt" and the entire proceeds from the sale of $q_{t-1}^{i}$ are distributed without loss to debt-holders (i.e. there are no reorganization or liquidation costs to debtholders). ${ }^{12,13}$

${ }^{10} \phi$ could, of course, easily be made to vary across firms. However doing this would merely complicate the notation without significantly altering the implications of the model. Note that $\phi^{-1}$ is a production function of the usual sort.

11 If there is increasing returns to scale, then $l$ increases with $q$, but less than proportionately.

12 Introducing reorganization costs has an impact on the results similar, but not quite identical, to the effect of a negative bankruptcy threshold. Also with reorganization costs firms will have an additional incentive (beyond the managerial penalty) to avoid bankruptcy.

13 In a fully dynamic model, bankruptcy occurs only when the lender refuses to lend to the borrower (or the borrower refuses to borrow.) That is, even if the firm cannot pay back its loans out of current proceeds, it will not go bankrupt unless the lender refuses to lend it the amount owed.

Our results are completely unaffected, however, if there is some other minimum bound (less than zero) which, 
Given [A2] and [A3] lenders to firm $i$ at the beginning of period $t$ earn returns which are a random variable whose value is resolved only when prices are revealed at the beginning of period $t+1$. If $P_{t+1}^{i}$ is high enough so that $A_{t+1}^{i} \geq 0$, then lenders receive a nominal return $R_{t}^{i}$. If $P_{t+1}^{i}$ falls below the level at which $A_{t+1}^{i}=0$, then lenders receive a nominal return $\left(\left(P_{t+1}^{i} q_{t}^{i} / B_{t}^{i}\right)-1\right) .{ }^{14}$ Firms go bankrupt if what they promise to pay exceeds their income; that is when

$$
\left(1+R_{t}^{i}\right) B_{t}^{i} \geq P_{t+1}^{i} q_{t}^{i}
$$

or, using (2) and (3),

$$
\tilde{u}_{t+1}^{i} \leq\left(1+R_{t}^{i}\right)\left[\frac{P_{t}}{P_{t+1}}\right]\left[\frac{w_{t} \phi\left(q_{t}^{i}\right)-a_{t}^{i}}{q_{t}^{i}}\right] \equiv \bar{u}_{t+1}^{i}
$$

where

$$
a_{t}^{i} \equiv \frac{A_{t}^{i}}{P_{t}} \equiv \text { real equity level of firm } i \text { at the beginning of period } t,
$$

and, thus,

$$
\begin{gathered}
\bar{u}_{t+1}^{i} \equiv \text { level of relative price in period } t+1, \tilde{u}_{t+1}^{i}, \\
\text { at which firm } i \text { is just solvent. }
\end{gathered}
$$

Thus, real returns to lenders are,

$$
\left(1+\tilde{R}_{t}^{i}\right)\left[\frac{P_{t}}{P_{t+1}}\right]=\left\{\begin{array}{ccc}
\left(1+R_{t}^{i}\right)\left[\frac{P_{t}}{P_{t+1}}\right] & \text { if } & \tilde{u}_{t+1}^{i} \geq \bar{u}_{t+1}^{i} \\
\frac{\bar{u}_{t+1}^{i} \cdot q_{t}^{i}}{w_{t} \phi\left(q_{t}^{i}\right)-a_{t}^{i}} & \text { if } & \tilde{u}_{t+1}^{i}<\bar{u}_{t+1}^{i}
\end{array}\right\} \text {, }
$$

if the firm's equity level falls below that level, it goes into bankruptcy.

14 If $P_{t} w_{t} \phi\left(q_{t}^{i}\right)>A_{t}^{i}$, then the firm is a net lender and the probability of bankruptcy is zero. For the remainder of the paper we will focus on the case where the reverse inequality holds. 
Strictly speaking $P_{t+1}$, looking forward from the beginning of period $t$, is a random variable.

However, in order to simplify the exposition, we will assume for the moment that there is relatively little uncertainty about future price levels (as opposed to the relative sectoral prices $\left.u_{t+1}^{i}\right)^{15}$ and, thus, that

$$
\begin{aligned}
P_{t+1}=P_{t+1}^{e} \equiv & \text { Expected price level at the beginning of period } t+1 \\
& \text { looking forward from the beginning of period } t
\end{aligned}
$$

Given equation (5), the expected real return to lenders to firm $i$ in period $t$ is

$$
E\left[\left(1+\tilde{R}_{t}^{i}\right)\right]\left[\frac{P_{t}}{P_{t+1}^{e}}\right]=\left(1+R_{t}^{i}\right)\left[\frac{P_{t}}{P_{t+1}^{e}}\right]\left[1-F\left(\bar{u}_{t+1}^{i}\right)\right]+\frac{q_{t}^{i}}{w_{t} \phi\left(q_{t}^{i}\right)-a_{t}^{i}} \int_{0}^{i} u_{t+1}^{i} x d F(x) .
$$

where $P_{t+1}^{e}$ can now be substituted for $P_{t+1}$ in the expression for $\bar{u}_{t+1}^{i}$. The first expression on the right-hand side of equation (7) represents the expected real return to lenders from those situations in which firm $i$ is solvent in period $t+1$. The second expression then represents the expected real return to lenders from situations in which firm $i$ is insolvent in period $t+1$. For determining the appropriate contractual rate of return, $R_{t}^{i}$, we next assume that

[A4] Lenders are perfectly informed ${ }^{16}$ and risk neutral which implies that

$$
E\left[1+\tilde{R}_{t}^{i}\right]\left[\frac{P_{t}}{P_{t+1}^{e}}\right]=1+r_{t} .
$$

Equations (4) and (8) can be solved for the equilibrium level of the contractual nominal interest rate, $R_{t}^{i}$, and the solvency relative price, $\bar{u}_{t+1}^{i}$, as functions of $q_{t}^{i}, a_{t}^{i}, w_{t}, r_{t}$ and $P_{t} / P_{t+1}^{e}$ :

15 This assumption may appear extreme and indeed will be violated in the next section of this paper. However, it can be relaxed without affecting the conclusions of the model in any fundamental way. Unfortunately, the price of such relaxation is considerable notational complexity since it requires definition of a bivariate price distribution covering both aggregate and sectoral prices; hence the use of the present assumption.

16 Clearly for the informational imperfections that interfere with the issue of equity to exist, lenders must not be able to use their information to purchase equity. The best way to interpret [A4] is that lending is done through institutions that are legally enjoined from purchasing stock. In any event, imperfect information on the part of lenders would intensify rather than alleviate the problems embodied in the model. 


$$
\begin{aligned}
& R_{t}^{i}=R_{t}^{i}\left(q_{t}^{i}, a_{t}^{i}, w_{t}, P_{t} / P_{t+1}^{e}, 1+r_{t}\right) \\
& \vec{u}_{t}^{i}=\bar{u}_{t}^{i}\left(q_{t}^{i}, a_{t}^{i}, w_{t}, P_{t} / P_{t+1}^{e}, 1+r_{t}\right)
\end{aligned}
$$

Then, substitution from $(9 \mathrm{~b})$ into $F(u)$ yields

$$
\text { Probability of Bankruptcy } \equiv F\left[\bar{u}_{t}^{i}\left(q_{t}^{i}, a_{t}^{i}, w_{t}, P / P_{t+1}^{e}, 1+r_{t}\right)\right]
$$

giving the probability of bankruptcy as a function of the decision variable, $q_{t}^{i}$, the state variable, $a_{t}^{i}$, and the parameters, $w_{t}$ (wages), $P_{t} / P_{t+1}^{e}$ (the expected change in the price level) and $r_{t}$ (the real interest rate).

In deciding upon a level of output, we will assume that the objectives of a firm's managers are described by the assumption that,

[A5] firm's select $q_{t}^{i}$ in order to maximize expected real profits (i.e. total sales minus repayment to lenders) minus an expected real cost of bankruptcy, i.e.

$$
\max \left[\frac{1}{P_{t+1}^{e}}\right] E\left[P_{t+1}^{i} q_{t}^{i}-\left(1+\tilde{R}_{t}^{i}\right) \max \left[\left[P_{t} w_{t} \phi\left(q_{t}^{i}\right)-A_{t}^{i}\right], 0\right]\right]-c_{t}^{i} F\left(\bar{u}_{t+1}^{i}\right) .
$$

Equation (10) is a simple way of capturing the hypothesis that firms act to avoid bankruptcy. As we shall see, this bankruptcy avoidance behavior induces a kind of risk aversion; ${ }^{17}$ similar results obtain whether these bankruptcy costs are viewed as real (managerial) reorganization costs associated with bankruptcy or if we view firms as maximizing the expected utility of profits with the utility function characterized by a declining marginal utility of profits and decreasing absolute risk aversion. 18

17 Strictly speaking this is true only if $c_{t}^{i} F$ is appropriately convex in $q_{t}^{i}$. Later we will impose conditions which will ensure that this is true.

18 See Greenwald-Stiglitz [1987]. 
We assume further that

[A6] Bankruptcy costs increase with the level of a firm's output:

$$
c_{t}^{i}=c q_{t}^{i}
$$

This assumption is made largely for analytic reasons; similar results hold for other bankruptcy cost functions as long as expected bankruptcy costs are convex in $q_{t}^{i}$. There are, however, three economic justifications which suggest that [A6] represents a plausible simplification. First, as firms become larger they presumably involve more managers whose loss of position, income and power in the event of insolvency is likely to increase. Bankruptcy should, therefore, be a more serious matter for General Motors than for a local grocery store. Since $q_{l}^{i}$ is the only scale variable in the model, having bankruptcy costs increase with $q_{t}^{i}$ is the only way to capture these scale effects. Second, a significant role of managers is choosing a level of output (in the model this is their only role). Bankruptcy with high levels of output should reflect unfavorably on their ability to do this. Since bankruptcy in the model is due to low prices, a high level of output in the face of these low prices may, retrospectively at least, imply unusually bad judgement by managers and may thus be unusually costly to their future prospects. ${ }^{19}$ Third, having bankruptcy costs depend on $q_{t}^{i}$ is necessary in order to ensure that the possibility of bankruptcy is never ignored. If there were a fixed cost of bankruptcy independent of the level of output, then profits, which are increasing in output, may grow so large relative to bankruptcy costs that bankruptcy becomes a negligible consideration. ${ }^{20}$ Since the purpose of this paper is to investigate the economic implications of conditions in which managers (or owners) are penalized for bad outcomes and are

\footnotetext{
19 This seems also likely to be true when firms suffer from degrees of financial distress short of bankruptcy.

20 In any case, we must assume that there is an upper limit on output (or that $\phi^{\prime}$ increases sufficiently rapidly) and the bankruptcy costs co-efficient $c$ is sufficiently large that a maximum for the objective function in [AS] exists. These technical assumptions are discussed in Appendix I.
} 
affected by the possibility of these penalties, assumption [A6] is a convenient way of ensuring that these conditions are met. Moreover with the addition of fixed bankruptcy costs there are reasonable circumstances under which the fundamental implications of the model with [A5] continue to hold (see Appendix I). ${ }^{21}$

Given [A2] and [A4], the objective function of [A5] can be written as

$$
\max _{q_{t}^{i}}\left[q_{t}^{i}-\left(1+r_{t}\right)\left(w_{t} \phi\left(q_{t}^{i}\right)-a_{t}^{i}\right)-c_{t}^{i} F\left(\bar{u}_{t+1}^{i}\right)\right]
$$

Under these assumptions, a firm's real output is, therefore, determined by real wages, real interest rates, real equity holdings, and relative price uncertainty. The first order condition ${ }^{22}$ for an interior maximum can now be written as

$$
1-\left(1+r_{t}\right) w_{t} \phi^{\prime}=\rho_{t}^{i}
$$

where $\rho_{t}^{i}$ is the marginal bankruptcy risk of firm $i$ in period $t$, i.e.

$$
\rho_{t}^{i}=\left(\frac{d c_{t}^{i}}{d q_{t}^{i}}\right) F+c f\left(\bar{u}_{t+1}^{i}\right) \frac{d \bar{u}_{t+1}^{i}}{d q_{t}^{i}} .
$$

If $\rho$ were zero, equation (13) would be the standard result that output should be increased to the point where the marginal product $\left(1 / \phi^{\prime}\right)$ equals the wage, taking into account the fact that the wage is paid the period before the output is received (and hence in present value terms, viewed at the time of production, wage costs are $\left.w_{t}\left(1+r_{t}\right)\right)$. Since $\rho$ is positive, the impact of bankruptcy risks is to restrict output; these risks drive a wedge between expected prices (i.e. 1) and marginal costs in the traditional sense (i.e. $\left.\left(1+r_{t}\right) w_{t} \phi^{\prime}\right)$.

21 The implied restriction in [A5] to a single period horizon is a matter of expositional convenience. The multiperiod maximization problem is examined in Appendix 1.

22 There are several restrictions that have to be imposed to ensure that the second order conditions are satisfied. These are discussed in Appendix I. 


\section{The Determinants of Marginal Bankruptcy Risk and Individual Firm Supply}

The marginal bankruptcy risk, $\rho_{\ell}^{i}$, depends, of course, on the level of output. In addition, it is a function both of the level of "equity" of the firm as well as the subjective probability distribution of the random variable $\bar{u}_{i+1}^{i}$. We can thus represent the supply function of a firm by an equation of the form

$$
q_{t}^{i}=g^{i}\left(w_{t}, r_{t}, a_{t}^{i} ; v_{t}^{i}\right)
$$

where $v_{t}^{i}$ represents a measure of the riskiness of the distribution $F$. It is easy to verify that

$$
\begin{aligned}
& g_{w}^{i}<0 \text { : real wage increases depress supply; } \\
& g_{r}^{i}<0 \text { : real interest rate increases depress supply }
\end{aligned}
$$

Our main concern, however, is with the effect of equity levels and uncertainty (risk) on production. It is possible to verify

Proposition 1. The higher the level of equity, the lower the marginal bankruptcy cost (risk permium) $\rho_{t}^{i}$, and hence the higher the level of production.

Proposition 2. Increases in the degree of uncertainty result in an increase in the marginal bankruptcy costs (risk premium) and hence in a lower level of investment. ${ }^{23}$

Under the assumption that $\phi$ is linear, up to a capacity constraint, we can show that investment, as a function of the equity level $a_{t}^{i}$, appears as in Figure 1. For the range within which the constant returns assumption holds, the elasticity of supply with respect to firm equity is unity. ${ }^{24}$

Accordingly,

23 The precise meaning of increases in uncertainty and the circumstances under which Proposition 2 is valid are discussed in Appendix I.

${ }^{24}$ More generally, with diminishing returns, the elasticity of supply is less than or equal to unity. 
Proposition 3. At least near the capacity level, output is a concave function of equity levels.

These three propositions are the heart of the firm level analysis: they imply that, if for some reason, a firm's equity is reduced (e.g. because the prices at which the firm is able to sell its goods are lower than anticipated) then, in subsequent periods, the firm's output will be reduced.

Moreover, our analysis suggests that for highly levered economies the output multipliers associated with equity injections may be substantial. For example if in equilibrium, equity represents one third of total capital (which in this circulating capital world is slightly less than output), then with constant returns to scale a $\$ 1$ increase in equity will yield $\$ 3$ of increased output. Note that there are a variety of ways that such equity injections may occur; unanticipated increases in the rate of inflation (monetary policy) as well as certain pump priming activities can result in substantial increases in the equity base of firms.

Later, we shall show the not surprising result that losses in equity will not instantaneously be restored, and thus the model has the immediate implication of persistence; a loss of equity at time $t$ results in lower output, not only at time $t$, but in subsequent periods as well.

The fact that the investment function is concave means that redistributions of wealth within the production sector may have deleterious consequences for production. Thus unanticipated increases in prices (say of oil) may have negative effects, and, at the same time, unanticipated decreases in prices of the same commodity may have negative effects. Propositions 2 and 3 together imply that increased uncertainty - both ex ante (anticipated) and ex post - depress production. This will be true whether the uncertainty is due to concerns about real shocks (changes in technology or preferences) or to concerns with the instabilities of macro-economic policy. 25

25 Since these policies generally impact different sectors differentially, uncertainty about these policies leads to uncertainty about relative prices. 
Aggregate Supply. An aggregate supply function can be derived straightforwardly by summing the supply functions of individual firms. For simplicity, we shall assume that all firms have the same production functions $(\phi)$ and face the same uncertainty $(F)$. We can then write aggregate output as

$$
q_{t}=\hat{g}\left(w_{t}, r_{t}, a_{t}^{1}, \ldots \ldots ; v\right)
$$

We can approximate the expression by taking a Taylor series expansion around the average level of firm equity holdings (under our symmetry assumptions), giving us an aggregate supply function of the form

$$
q_{t}=g\left(w_{t}, r_{t}, a_{t} ; v, \sigma\right)
$$

where $\sigma^{2}$ is the variance of firm equity levels. The comparative static properties of this aggregate supply function will, in general, mirror those of a representative firm's output (with the additional effect noted that an increase in the dispersion of equity ownership will generally lower output).

Since, in this model, output is restricted as a result of the failure in the market for sharing the risk of bankruptcy, it is plausible to think of higher output as implying an improvement in social welfare. ${ }^{26}$

\section{General Equilibrium and Productivity Growth}

In order to simplify the model as far as possible, we will deal for the moment only with a constant-returns-to-scale technology in which

26 Because increases in output are likely to have distributional effects, they may well not be Pareto improvements. We use the term "welfare enhancing" in a rather loose sense, i.e. that gainers could more than compensate losers. 


$$
c_{i t}=\frac{q_{i t}}{n_{t}}
$$

where $n_{t}$ is an economy-wide productivity index. Then the supply function for an individual firm becomes

$$
q_{i t}=g^{i}\left(\frac{w_{t}}{n_{t}}, r_{t}, v_{t}^{i}\right) a_{t}^{i}
$$

since under those circumstances output is linear in firm equity and actual wage levels can be converted to "effective" wage levels by dividing by the productivity index, $n_{t}$. Aggregate supply can then be written as

$$
q_{t}=g\left[\frac{w_{t}}{n_{t}}, r_{t}, v\right) a_{t}
$$

and the aggregate demand for labor will be

$$
l_{t}^{D}=\frac{q_{t}}{n_{t}}=g\left[\frac{w_{t}}{n_{t}}, r_{t}, v\right] \frac{a_{t}}{n_{t}}
$$

Next continuing to make the model as simple as possible, we will assume that consumer behavior can be described by the behavior of a single, infinitely-lived representative consumer. Furthermore, we will assume that this representative consumer may borrow and lend freely at the competitive real rate of interest, $r_{t}$, and consequently faces a single lifetime budget constraint of the form

$$
\sum_{j=0}^{\infty}\left(z_{t+j}-w_{t+j} l_{t+j}\right) \pi_{t, j}=k_{t}
$$

where

$$
z_{t+j} \equiv \text { real consumption in period } t+j
$$




$$
\begin{aligned}
& l_{t+j} \equiv \text { hours worked in period } t+j, \\
& \pi_{t, j} \equiv \prod_{i=0}^{j}\left[\frac{1}{1+r_{i}}\right] \text { (and } 1 \text { for } j=0 \text { ) }
\end{aligned}
$$

and

$$
k_{t} \equiv \text { real wealth in period } t \text {. }
$$

Finally, we will assume that the representative consumer has a utility function of the form

$$
\sum_{j=0}^{\infty}\left[\frac{1}{1+\delta}\right] j\left[z_{t+j}-v\left(c_{t+j}, n_{t}\right)\right]
$$

where $v^{\prime}>0$ and $v^{\prime \prime}>0$ and $\dot{n}_{t}$ enters the utility function because technological progress increases the productivity of leisure as well as labor.

Under these circumstances, equilibrium in the aggregate market for goods and services is characterized by the conditions ${ }^{27}$

$$
r_{t}=\delta
$$

and consumption equals output,

$$
z_{t}=q_{t}
$$

In addition, the supply of labor is an increasing function only of the wage in the current period, $w_{t}$, and $n_{t}$. The real wage is then determined by an equilibrium in the labor market of the form

$$
l_{t}^{D}=q_{t} / n_{t}=s\left(w_{t}, n_{t}\right), s^{\prime}>0 .
$$

where $s$ is the supply function for labor. ${ }^{28}$ Finally, as a benchmark case, we will consider the

27 That is, the utility function (16) ensures that since the individual is willing to trade off a dollar of consumption at time $t+1$ for $1+\delta$ at $t$, regardless of the levels of consumption of goods or leisure, the market rate of interest must be $\delta$.

28 Note that this formula can be used to reconcile the seeming discrepancy between labor supply studies based on long-run time series (which suggest a backward bending labor supply curve) and cross-sectional studies which exhibit a generally positive, but small, supply elasticity. 
situation in which $s\left(w_{t}, n_{t}\right)$ can be written $s\left(w_{t} / n_{t}\right)$, i.e. productivity improvement in leisure are directly proportional to labor productivity improvements. This can, then, be solved to yield real wages as a function of aggregate output of the form

$$
\frac{w_{t}}{n_{t}}=\Psi\left(q_{t} / n_{t}\right)
$$

where $\Psi^{\prime \prime}=(1 / s)>0$. Finally, substitution from the labor and capital market equilibria into the aggregate supply function yields a relationship of the form

$$
\frac{q_{t}}{n_{t}}=g\left[\Psi\left(\frac{q_{t}}{n_{t}}\right), \delta, v\right]\left[\frac{a_{t}}{n_{t}}\right)
$$

which can be solved to yield

$$
\hat{q}_{t} \equiv \frac{q_{t}}{n_{t}}=H\left[\frac{a_{t}}{n_{t}}, v\right]
$$

where $H^{\prime}=\left(g_{a} /\left(1-g_{w} \Psi^{\prime}\right)\right)=\left(g_{a} s^{\prime} /\left(s^{\prime}-g_{w}\right)\right)>0$. Thus, in each period output is determined by the level of equity and movements in output over time will be driven by movements in the level of equity where both are deflated by the productivity index $n_{t}$.

Equity in period $t+1$ consists of equity in period $t$ plus earnings on that equity (we assume that new equity sales less dividends are zero). In nominal terms,

$$
\bar{A}_{t+1}^{i}=\bar{P}_{t+1}^{i} q_{t}^{i}-\left(1+\bar{R}_{t}^{i}\right)\left[P_{t} w_{t} q_{t}^{i} / n_{t}-A_{t}^{i}\right]
$$

Summation over firms and the taking of expected values yields

$$
\begin{aligned}
E\left[A_{t+1}\right] & =P_{t+1} q_{t}-\left[P_{t+1}^{e}\right] E\left[\frac{\left(1+\bar{R}_{t}^{i}\right) P_{t}}{P_{t+1}^{e}}\right]\left(w_{t} q_{t} / n_{t}-a_{t}\right) \\
& =P_{t+1} q_{t}-\left[P_{t+1}^{e}\right](1+\delta)\left(w_{t} q_{t} / n_{t}-a_{t}\right)
\end{aligned}
$$


where unsuperscripted variables now denote aggregate quantities. Division by $P_{t+1}$ to convert to real terms yields an equation for real equity levels in period $t+1$ of the form

$$
a_{t+1}=q_{t}-\left(\frac{P_{t+1}^{e}}{P_{t+1}}\right)(1+\delta)\left(w_{t} q_{t} / n_{t}-a_{t}\right)
$$

Equations (22) and (23) together with whatever determines "price shocks" (i.e. the variable $P_{t+1}^{e}\left(P_{t+1}\right)$ now determines the dynamic behavior of output in the model.

In order to examine this behavior consider the perfect foresight equilibrium in which expected and actual prices are equal. Then, after division of both sides by $n_{t+1}$, equation (23) becomes

$$
\begin{aligned}
\frac{a_{t+1}}{n_{t+1}} & =\frac{n_{t}}{n_{t+1}}\left[\frac{q_{t}}{n_{t}}-(1+\delta)\left[\frac{w_{t}}{n_{t}} \cdot \frac{q_{t}}{n_{t}}-\frac{a_{t}}{n_{t}}\right]\right) \\
& =\left[\frac{n_{t}}{n_{t+1}}\right]\left[H\left[\frac{a_{t}}{n_{t}}, v\right]-(1+\delta)\left[\psi \cdot H-\frac{a_{t}}{n_{t}}\right]\right) \\
& \equiv\left(\frac{n_{t}}{n_{t+1}}\right] G\left[\frac{a_{t}}{n_{t}}, v\right] .
\end{aligned}
$$

It now only remains to specify how aggregate productivity improvement $\left(n_{t} / n_{t+1}\right)$ takes place.

We will assume that learning-by-doing underlies productivity growth and that learning-bydoing is proportional to total employment. Then

$$
\frac{n_{t}}{n_{t+1}}=\gamma\left(l_{t}\right)=\gamma\left(\frac{q_{t}}{n_{t}}\right]=\gamma\left[H\left[\frac{a_{t}}{n_{t}}, v\right]\right]
$$

where $\gamma \leq 1, \gamma<0, \gamma^{\prime}>0$ (by assumption). Substitution into equation (24), then yields

$$
\hat{a}_{t+1} \equiv\left[\frac{a_{t+1}}{n_{t+1}}\right]=\gamma\left[\frac{a_{t}}{n_{t}}, v\right] G\left[\frac{a_{t}}{n_{t}}, v\right] \equiv J\left[\frac{a_{t}}{n_{t}}, v\right] \equiv J\left(\hat{a}_{t}, v\right)
$$


which characterizes the dynamic behavior of the system.

The model of learning which we have employed, though commonly used, has some strong assumptions and properties. We have assumed in particular that learning is economy wide; there are, in effect, one hundred percent spill-overs. Learning by doing, it has long been recognized, gives rise to a kind of increasing returns or non-convexity, and increasing returns pose difficult problems for equilibrium theory. The singular case in which this is not true (in the absence of risk) is that where there are one hundred percent spill-overs. ${ }^{29}$

Also, while other forms of increasing returns pose problems for standard formulations (such as those of Romer [1988] and Lucas [1988]) they present no difficulty for us, for two reasons. First, risk- (or bankruptcy-) aversion implies that even with increasing returns to scale in production, there can be more than one firm in the market in equilibrium. Secondly, our model can easily be extended to incorporate monopolistic competition (or other forms of imperfect competition).

\section{Dynamic Behavior}

The dynamic behavior implied by equation (25) can be summarized in terms of Figure 2 which plots $\hat{a}_{t+1}\left(\equiv a_{t+1} / n_{t+1}\right)$ as a function of $\hat{a}_{t}\left(\equiv a_{t} / n_{t}\right)$. At low "effective" equity levels (i.e. low $\hat{a}_{t}$ ), demand for labor and wages will be low and profits correspondingly high. This will lead to relative rapid equity accumulation from reinvested profits and relatively low levels of productivity growth (i.e. $\gamma$ near one). We will assume that there exists an $\hat{a}_{t}$ low enough such that $J\left(\hat{a}_{t}\right)>\hat{a}_{t}$. Then as $\hat{a}_{t}$ rises, wages rise, profit margins fall and reinvested earnings per " effec-

29 See Dasgupta and Stiglitz [1988] for an analysis of the imperfectly competitive equilibria which result when spill-overs are even slightly less than one hundred percent. 
tive" unit should fall. At the same time, the rate of productivity growth increases and consequently $\gamma$ falls. For these reasons, $J\left(\hat{a}_{t}\right)$ should at some point cross the $45^{\circ}$ from above as shown in Figure 2. The point of crossing where

$$
a^{*}=J\left(a^{*}\right)
$$

represents a steady-state equilibrium at which the "effective" equity level is constant. At each such equilibrium (given a fixed "uncertainty" parameter $v$ ), the rate of learning-by-doing productivity improvement is different and hence so is the growth rate of output. Thus, in contrast to most growth models in which steady-states differ according to the level but not the growth rate of output, different steady-states in this model are associated with different growth rates. Decreasing returns to the capital accumulation process do not arise in this model as they do in more conventional growth models.

At the same time, cyclical disturbances in the model may have permanent effects both on the level of output and, in some cases, on its growth rate.

First, even with $P_{t+1}=P_{t+1}^{e}$ in every period, deterministic cycles of multiple periodicity may occur if the slope of the curve, $J$, is sufficiently highly negative when it crosses the fortyfive degree line (see Figure 2). ${ }^{30}$ If these conditions are met the resulting "real" cycles bear at least a casual resemblance to the "wage-shock" models which have been discussed, at least informally, in the empirical literature. ${ }^{31}$ Prosperity in the form of rising output and firm equity levels leads to both rising wages, which reduces profits and internal funds flows. These in turn

30 See Grandmont [1985] for a discussion of these cycles in a slightly different context.

31 Theoretical models in which growth depends on profits, and profits depend on wages, have been formulated by Goodwin [1981] and Akerlof and Stiglitz [1969].

Kaldor, Marx, and Rosa Luxemberg all formulated models in which capital accumulation depended on profits. They seemed (implicitly) to have recognized the difference between funds that were inside the firm and funds that were outside. But they had no theoretical model to motivate the distinction, and thus this line of investigation was dismissed, not because it had been proven empirically wrong, but because it was viewed to be simply too ad hoc. 
ultimately reduce equity levels and output, which both restores profitability (as wages fall) causing the cycle to begin again.

If $J^{\prime}$ is always greater than zero, then no such cycles are possible and convergence to the steady-state is monotone. However, random price shocks, which lead to unexpected fluctuations in the real value of debt obligations and hence in real equity level, will lead to output fluctuations which persist over several periods. Consider, for example, an unexpectedly low level of $P_{t+1}$ (i.e. $P_{t+1}<P_{t+1}^{e}$ ). From equation (24), this will lead to an immediate and substantial drop in equity levels away from the steady-state level, $a^{*}$, (assuming that the economy started at $a^{*}$ ) with an associated drop in output. The economy will return to $a^{*}$ (and the associated "fullemployment" level output) only slowly as a result of successive positive increments to $\hat{t}_{t}$. In the intervening period output and learning-by-doing are reduced and hence the overall productivity level suffers a permanent set back. In this case, the growth rate eventually returns to its original steady-state level, but the loss in productivity improvement during the intervening period of low output is never recovered. Thus, while the economy eventually returns to the steady state, characterized by $(a / n)^{*}$, the value of $n_{t}$ at any date is different from what it would have been in the absence of the disturbance. The stochastic process for the economy's output exhibits, to use the fashionable term, a unit root.

\section{Sources of Price Shocks}

There are innumerable possible ways to model the sources of these price shocks. The simplest is to assume that output is sold on a large international market and international prices vary in response to forces which are external to the economy in question. A more traditional source of such "shocks" would be a monetary sector which determines the aggregate price level. From this perspective, an unexpectedly low level of $P_{t+1}$ might be associated with either an 
unexpectedly low level of money supply or, for some money demand specifications, with an unexpectedly low level of consumption demand. Explorations of these phenomena are contained in Greenwald-Stiglitz [1986], but they add relatively little (at the cost of some complexity) to understanding of the basic characteristics of the model in question. Also, as we noted earlier, macroeconomic shocks, whether monetary or fiscal, will have effects not only on average prices but also on the relative prices upon which we focus in this paper.

\section{Comparative Statics}

The model can easily be used to analyze the consequences of a variety of changes in policy or in the environment. For example, structural changes in financial markets which assist in the accumulation of equity capital (shifting the function $J$ vertically upward - see Figure 2) may increase not only the current level of output, but also the long term rate of growth of output. However, a detailed analysis of the steady-states of the model is most easily carried out in terms of a joint analysis of $\hat{a}($ i.e. $a / n)$ and $\hat{q}$ (i.e. $q / n)$.

As a point of departure in doing this, we will continue to consider the case of constant returns to scale. Then from equation (20) above

$$
\hat{q}=g[\psi(\hat{\bar{q}}), \bar{\delta}, v] \hat{a}
$$

If this relationship is rewritten as

$$
\hat{a}=\hat{q} / g
$$

it can be described as an equity requirements equation. For any given levels of relative price uncertainty, $v$, and the discount factor, $\delta$, equation (29) describes the level of equity necessary to support a level of production $\hat{q}_{t}$. The elasticity of this relationship is

$$
\frac{\hat{q}}{\hat{a}} \cdot \frac{d \hat{a}}{d \hat{q}}=1-\hat{a} \cdot g_{w} \cdot \psi^{\prime} \geq 1
$$


since $g_{w}<0, \phi^{\prime}>0$ and $\hat{a}>0$. This curve is plotted in Figure 3.

Combining equations (24) and (26) yields a second steady-state relationship of the form

$$
\hat{a}=\frac{\gamma(\hat{q}) \hat{q}(1-(1+\delta) \psi(\hat{q}))}{1-\gamma(\hat{q})(1+\delta)}
$$

This can be thought of as a steady-state equity supply equation. It represents the steady-state level of equity that would result from a steady-state output level $q$ (given a discount rate, $\delta$ ). In examining the slope of this relationship, there are three distinct effects of output changes on the supply of equity. Along the equity supply curve,

$$
\frac{\hat{q}}{\hat{a}} \frac{d \hat{a}}{d \hat{q}}=1+e_{\gamma}\left(\frac{1}{1-\gamma(1+\delta)}\right)-\frac{1}{e_{s}}\left[\frac{(1+\delta) \psi}{1-(1-\delta) \psi}\right]
$$

where $e_{\gamma}$ is the elasticity of the learning function with respect to output (which is negative since $\gamma$ is defined as $n_{t} / n_{t+1}$ and the productivity index $n$ grows more rapidly at higher levels of output) and $e_{s}$ is the labor supply elasticity (which is positive since for our utility function there are no income effects). The first term in this expression (i.e. 1) represents the direct contribution of higher output to higher equity levels through higher profits (profit per unit of output is always positive because bankruptcy risk holds output below the zero profit level). The second term, $e_{\gamma} /(1-\gamma(1+\delta))$, is a negative productivity growth effect; the higher the level of output the higher the rate of productivity growth and the harder it is to maintain existing levels of equity per effective unit of labor (remember that $\hat{a}_{t}=a_{t} / n_{t}$ ). The third term in equation (31) is a negative wage effect. Higher levels of output drive wages up which reduces profits and, hence, steady-state equity levels. Because these final two terms are negative, ${ }^{32}$ the elasticity of the equity supply

32 The term $(1-(1+\delta) \psi)$ which represents expected profits per unit of output is negative because bankruptcy risk implies that firms always produce at a point of positive expected profit. Also, in the relevant region of the steady-state equilibrium $\gamma(1+\delta)$ must be less than unity - see Figure 2 - and, thus, $1-\gamma(1+\delta)$ is greater than zero. 
curve is less than unity and may be negative. In fact, it is likely to be negatively sloped. With a labor supply elasticity of 0.5 and interest adjusted labor costs (i.e. $(1+\delta) \psi$ ) of 75 percent of output, the final negative term in equation (31) is minus six, which significantly outweighs (by itself) the initial positive term.

A steady-state equilibrium occurs only where the equity demand function, equation (29), intersects the equity supply function, equation (30). Only at this point is the steady-state level of equity (per effective unit of labor) supplied by the corresponding steady-state level of output (again per effective unit of labor) just equal to the steady-state level of equity necessary to sustain that level of output (i.e. the equity demanded by that level of output). Analysis of the steady-state equilibrium in terms of these two curves is useful because it helps to isolate the consequences of various changes in the underlying parameters of the model (e.g. relative price uncertainty).

It is immediately clear that in the model with constant returns to scale there is a unique steady-state equilibrium. The elasticity of the equity supply curve is less than one which is, in turn, less than the elasticity of the equity demand curve. Thus, whenever the equity supply and demand curves intersect, the supply curve, being less steeply sloped, must cut the demand curve from above and only one such intersection may exist. 33

An increase in the perceived uncertainty of future relative prices, $v$, will in general lead to a

${ }^{33}$ Modifications of the basic constant returns to scale model presented here may easily lead to multiple equilibrium. For example, with a backward bending labor supply curved (ruled out by the simple utility function of equation (16), but certainly possible in practice) the equity supply curve may have an elasticity greater than one and hence greater than that of the equity demand curve. Equivalently, with increasing returns to scale in production, the equity required to support a given level of production might increase less than proportionately with output (since input requirements would increase less than proportionately with output) and the equity demand curve would have an elasticity of less than one. In both cases, multiple intersections of the equity supply and demand curves are possible. Note also that in the increasing returns case, increasing returns in production would still lead to well defined competitive firm output levels since bankruptcy risk would limit firm production levels. 
reduction in the level of output and growth at each level of $\hat{a}$. If the increase in uncertainty is permanent, then the drop in output and growth will be permanent. This is equivalent to an upward shift in the equity requirements (demand) equation. Greater uncertainty requires that firms have greater equity bases to support any given level of output. At the same time, the equity supply equation is not affected. Hence (see Figure 3A), steady-state output always declines, and as output declines so too do the rates of learning-by-doing and growth. ${ }^{34} \mathrm{~A}$ time path of output (adjusted for productivity, i.e. $\hat{q}_{t}$ ) may also be inferred, if firm equity levels are assumed to adjust only slowly to an initial uncertainty shock. In the "normal" case where the equity supply curve slopes downward, an upward shift in the equity requirements curve leads to a large initial drop in output which is then gradually (and partially) offset as firms accumulate equity (see Figure 3A).

A shift in the labor supply equation affects both the equity supply curve and the equity requirements curve. An increase in the wage required to elicit any given labor supply will shift the equity requirements curve up and the equity supply equation down. Thus, steady-state output and growth are unambiguously reduced, while steady-state equity levels may either rise or fall (see Figure 3B).

\section{Conclusion}

The model described above is one in which financial market imperfections create a situation where certain kinds of financial capital (in this case equity capital) act as an independent input to the process of production and investment. Then, because this resource is generated endogenously by the interaction of financial and real markets, output and rates of growth depend

\footnotetext{
${ }^{34}$ Steady-state equity levels, $\hat{a}$, may either increase or decrease depending upon whether the equity supply curve is downward or upward sloping respectively.
} 
on these interactions. Such circumstances would explain among other phenomena:

(1) Why high rates of anticipated inflation (usually associated with high rates of relative price variability) have typically been associated with deterioration in observed rates of productivity growth. This would be an example of the kind of uncertainty shock discussed above. 35

(2) Why cyclical expansions are associated with increases in measured productivity. An unexpected expansion would lead to unexpectedly high price levels and an increase in firm equity (at the expense of debtholders). The increase in the level of "equity" input would then tend to increase the productivity of other inputs (hence, the widely observed Okun's Law phenomenon). ${ }^{36}$

(3) Why firms tend to grow at proportional rates independent of their sizes (Gibrat's Law). Firm growth in the model is governed by equity accumulation whose proportional change depends on factors other than size. But if these factors are fixed, Gibrat's Law holds precisely.

(4) Why there are no apparent decreasing returns to aggregate output growth. Japan has seemed to grow for decades, without the kind of diminishing returns that conventional Solow growth theory would have suggested should have set in. (For more empirical evidence on this, see Romer [1986]).

35 Unanticipated inflation affects the market directly: higher prices mean that firms pay back less in real dollars, increasing real equity levels and output. Eventually, however, the economy returns to its old steady-state (although at a higher than otherwise level of $q_{t}$ and $n_{t}$ ).

36 Our explanation is not inconsistent with models that attribute Okun's law to labor hoarding. Those models do not explain why, if labor is a quasi-fixed factor and markets are competitive, firms do not produce more. We provide an explanation, based not so much on firms' abilities to sell as on their willingness to produce. There is another explanation, based on the hypothesis of imperfect competition, with the degree of monopoly increasing in a recession. While we do not deny the possibility of imperfect competition (which can readily be incorporated in our model) the explana explanations for the cyclical variability in the degree of monopoly seem to us unpersuasive. See Hall [1988] and Stiglitz [1985]. 
In our model, there are two factors offsetting the onset of diminishing returns. First, there is the direct effect of learning by doing: the more production, the more the learning by doing. Secondly, there is an indirect effect, as the increased productivity results in higher profitability and equity accumulation which translates, in time, into increased output and productivity growth.

Finally, it should be noted that models in which productivity growth results from active investments in R\&D rather than passive learning-by-doing produce qualitatively similar results to those described above. In these models, with risk averse firms (subject to decreasing absolute risk aversion) and equity market constraints, the level of $R \& D$ investment is determined by the level of firm equity which is determined, in turn, by the kind of dynamic process described above. 


\section{Appendix I}

\section{Firm Supply Behavior}

Suppressing the time and firm subscripts for the sake of expositional convenience, a representative firm's optimization problem is to

$$
\max _{q}[q-(1+r)(w \phi-a)-c q F(\bar{u})]
$$

Also we can rewrite equations (7) and (8) giving the nominal contractual rate of interest charged the representative firm as

$$
h \equiv(1+r)\left[\frac{w \phi(q)-a}{q}\right]=\bar{u}(1-F(\bar{u}))+\int_{0}^{\bar{u}} x d F(x)=z(\bar{u}) .
$$

In examining this decision problem it will be useful to look first at the constant-returns-toscale case, in which with a suitable choice of units

$$
\phi(q)=q
$$

Given (A-3), the decision problem of the representative firm can be rewritten

$$
\max _{q}[a(1+r)+q[1-(1+r) w-c F(\bar{u})]]
$$

subject to (A-2) where $h=(1+r)(w-(a / q))$. The first order condition can thus be written as

$$
1-(1+r) w=c\left[F+\frac{(1+r)(a / q) f}{1-F}\right] \equiv \rho(\bar{u}(q))
$$

where we have made use of the fact that, from $(A-2)$,

$$
z^{\prime}=1-F
$$

and 


$$
\frac{d \bar{u}}{d q}=\left(1 / z^{\prime}\right) \frac{d h}{d q}=-\left(1 / z^{\prime}\right)\left(h-(1+r) w \phi^{\prime}\right) / q
$$

or, in the case under consideration where $\phi=q$,

$$
d \bar{u} / d q=\frac{(1+r) a}{q^{2}(1-F)} .
$$

Equation (A-5) can be rewritten as

$$
q=a c(1+r) f /[(1-F)(m-c F)]
$$

where $m \equiv 1-(1+r) w$. The RHS of (A-8) is just a function of $\bar{u}$, which, from (A-7), is just an (increasing) function of $q$.

\section{Solving for the Equilibrium Level of Output}

(a) We first show that, under a fairly weak condition to be given below, there exists a bounded solution to $q$. To derive this condition, we first need to observe that as $q$ increases toward infinity, $h$ tends toward $(1+r) w$ and $\bar{u}$ approaches a unique finite limit $\bar{u}_{o}$ which solves the equation

$$
(1+r) w=\bar{u}_{o}\left(1-F\left(\bar{u}_{o}\right)\right)+\int_{0}^{\bar{u}_{o}} x d F(x) .
$$

The last step in this argument follows from the facts that in any equilibrium with positive output $(1+r) w<1$ and that the right hand side of (A-9) increases continuously and monotonically to a limit $E(x)=1$ as $\bar{u}_{o}$ goes toward infinity. Thus, as $q$ goes toward infinity, the probability of bankruptcy $F(\bar{u})$ approaches a finite limit $F\left(\bar{u}_{o}\right) \equiv F_{o}$. In order that a maximum to the firm's decision problem exist, it must then be the case that, at the equilibrium level of real wages and interest rates,

$$
1-(1+r) w-c F_{o}<0
$$


Otherwise the firm's objective function, (A-4), can be increased without bound. Thus, we will assume that $c$ is sufficiently large that (A-10) holds and consequently that there is a finite optimal level of output.

(b) For $a>0$, optimal output is positive (since $a>0$ and $1>(1+r) w$ imply positive profits with no risk of bankruptcy for small positive $q$ ); while for $a=0$, optimal $q=0$ since, under those circumstances, $h=(1+r) w$ and $F(\bar{u})=F_{0}$ for all $q$. Thus, if $F$ is sufficiently smooth, the firm's objective function is locally continuous and twice differentiable at the optimal level of output. 37

\section{Second Order Condition}

With a constant-returns-to-scale technology, the second order condition takes the form

$$
-\frac{c(1+r)^{2} a^{2}}{(1-F)^{2} q^{3}}\left[f^{\prime}+\frac{f^{2}}{1-F}\right]<0
$$

where $f^{\prime}$ is the first derivative of the density function $f$ evaluated at the optimal bankruptcy point. At the optimal level of output, therefore,

$$
f^{\prime}+\frac{f^{2}}{1-F}>0
$$

Note that since, in practice, bankruptcies appear to be relatively rare for moderate and largesized firms (i.e. they occur with probability less than one half in any decision period), firms operate with bankruptcy levels in the lower tail of the price distribution; if that distribution is single peaked, $f^{\prime}$ will be positive at relevant levels of output. This, in turn, means that (A-12) is satisfied.

\footnotetext{
37 We will ignore the possibility that two locally separate values of $q$ produce the same optimal value of the firm's objective function.
} 
Note, too, that if the distribution $F$ is characterized by an increasing hazard function (i.e. $f / 1-F$ is monotonically increasing), then (A-11) is satisfied globally.

\section{Graphical Solution and Comparative Statics}

With constant returns to scale, the marginal return to production, ignoring bankruptcy costs, is fixed (at what we have called $m$ ), while the marginal bankruptcy cost, $\rho$, increases with $q$. At any maximum, the $\rho(q)$ curve cuts $m$ from below; the discussion in the preceding paragraph argued that normally there will be only one relevant intersection, and provided a global condition for a unique intersection (see figure 4).

The simplicity of the structure of the first order conditions makes comparative statics analysis relatively easy.

First, note that since, from (A-2), $\bar{u}$, the bankruptcy relative price, is a function only of $a / q, \rho$ is a function only of $a / q$. Hence, an increase in $a$ accompanied by an equiproportionate increase in $q$ leaves $\rho$ unchanged: With constant returns, $d \ln q / d \ln a=1$.

Secondly, an increase in $w$ reduces $m$ (the marginal return from production, ignoring bankruptcy costs), while from (A-2), at any $q, \bar{u}$ increases; so long as the second order condition is satisfied, this implies that $\rho$, the marginal bankruptcy cost, is increased. ${ }^{38}$ Thus, as figure 4 illustrates, output is unambiguously reduced.

Thirdly, an increase in $r$ reduces $m$, while, from (A-2), at any $q, \bar{u}$ increases; again, so long as the second order condition is satisfied, this implies that $\rho$, the marginal bankruptcy costs, is increased, and output is reduced.

\footnotetext{
${ }^{38} d \rho / d w=c f d \bar{u} / d w+(d \rho / d q) q^{2} / a$ where $d \bar{u} / d w=(1+r) / 1-F$ and $(d \rho / d q)>0$ by the second order condition.
} 
Finally, we examine the effect of an increase in uncertainty. This shifts the values of $f$ and $F$ corresponding to any set of values of the other parameters. Straightforward differentiation shows that, at the optimum,

$$
d \rho / d F=c+(m-c F) /(1-F)>0
$$

At the same time

$$
d \rho / d f=(m-c F) / f>0 .
$$

We focus our attention on the situation where bankruptcy probabilities (in any period) are low. If an increase in uncertainty increases the likelihood of bad events ( $F$ and $f$ both increase), then $\rho$ will increase, and output will be reduced. Even if $F$ increases, but $f$ decreases uncertainty will increase $p$ (reduce output) so long as the hazard rate is increased. ${ }^{39}$

\section{The General Case}

The first and second order conditions for the general case $\left(\phi^{\prime \prime}<0\right)$ as well as the comparative static properties can easily be derived. We simply present the relevant formulae.

(a) First order condition

$$
1-(1+r) w \phi^{\prime}=c F+\frac{c f(1+r)}{q(1-F)}\left[a+w\left(\phi^{\prime} q-\phi\right)\right]
$$

Note that $\phi^{\prime} q-\phi>0$ since $\phi^{\prime \prime}>0$ and $\phi(0)=0$

(b) The second order condition for an interior maximum is,

$$
-(1+r) w \phi^{\prime \prime} \beta-\alpha \leq 0
$$

where

39 Denote the change in the distribution by $d y$. Then we can write the total effect on $\rho$ as $d \rho / d y=c d F / d y+(m-c F) d \ln \{f / 1-F\} / d y$. Hence, so long as the cumulative of the bad states is increased and the hazard function is increased, $\rho$ is increased. 


$$
\begin{aligned}
\beta & \equiv 1+\frac{c f}{1-F}>0, \\
\alpha & \equiv \frac{c q}{(1-F)^{2}}\left[\frac{d h}{d q}\right]^{2}\left[f^{\prime}+\frac{f^{2}}{1-F}\right], \\
\frac{d h}{d q} & =\frac{(1+r) w}{q^{2}}\left[\phi^{\prime} q-\phi+a / w\right]
\end{aligned}
$$

and the various distribution and density functions (i.e. $F, f$ and $f^{\prime}$, the derivative of the density function) are evaluated at $\bar{u}$. A sufficient condition for this is that (A-12) holds.

The comparative statics follow along similar lines to those presented before. If we define $m(q)$ as the marginal return to production, ignoring bankruptcy costs, now $m(q)$ is a decreasing function of $q$. Moreover, now, $\rho$ is a function of $w$ not only indirectly, through the effect of $w$ on $\bar{u}$, but directly. Nonetheless, the basic qualitative properties remain.

First, for a change in real equity,

$$
\frac{d q}{d a}=\left(\frac{q}{a}\right)\left[\frac{\alpha \zeta}{\alpha+(1+r) w \phi^{\prime \prime} \beta}\right] \geq 0
$$

where

$$
\zeta \equiv\left(\frac{1}{1+(w / a)\left(\phi^{\prime} q-\phi\right)}\right) .
$$

With decreasing returns $(a / q)(d q / d a)<1$ and proportional increases in equity lead to less than proportional increases in output. In particular, note that if marginal labor requirements increase greatly beyond some point, $\phi^{\prime} q-\phi$ becomes large and hence $\zeta$ becomes small. Moreover $q / a$ is becoming smaller and smaller. Hence, $d q / d a$ eventually becomes quite small. ${ }^{40}$

40 On the other hand, one cannot ensure that $q$ is everywhere a concave function of $a$. The second derivative of $q$ with respect to $a$ involves, among other things, terms in $\phi^{\prime \prime \prime}$, about which we have so far made no assumptions. 
For changes in wages,

$$
\frac{d q}{d w}=-\left[\frac{q}{w}\right]\left[\frac{\alpha \gamma+(1+r) w\left(\phi^{\prime} / q\right) \beta}{\alpha+(1+r) w \phi^{\prime \prime} \beta}\right] \leq 0
$$

where

$$
\gamma \equiv\left[\frac{w \phi}{a}\right] \zeta \equiv w \frac{\phi}{a+w\left(\phi^{\prime} q-\phi\right)}
$$

If $\phi^{\prime \prime}=0$, then $(w / q)(d q / d w)<-1$, since $w \phi>a$. On the other hand, if marginal costs increase very rapidly as a firm approaches its "capacity" limit (i.e. $\left.\phi^{\prime \prime} \gg \phi^{\prime} / q, \phi^{\prime} q \gg \phi\right)$, then near "capa$\operatorname{city"}^{\prime \prime}(w / q)(d q / d w)>-1$

For changes in real interest rates,

$$
\frac{d q}{d r}=-\left[\frac{q}{1+r}\right]\left[\frac{\alpha \eta+(1+r) w\left(\phi^{\prime} / q\right) \beta}{\alpha+(1+r) w \phi^{\prime \prime} \beta}\right] \leq 0
$$

where

$$
\eta \equiv\left[\frac{w \phi}{a}-1\right] \zeta=\gamma-\zeta
$$

Thus $(w / q)(d q / d w) \leq((1+r) / q)(d q / d r)$ and wages have a greater proportional negative impact on real output than interest rates.

The analysis of the effects of changes in uncertainty parallels that of our earlier discussion. Inspection of the first order condition shows that so long as the uncertainty increases the cumulative probability of bad states $(F)$ and the hazard rate $f / 1-F$, the marginal bankruptcy cost is increased and output is reduced.

\section{More General Bankruptcy Cost Functions}

An obvious extension of the form of bankruptcy costs is to add a fixed component to the 
bankruptcy cost function so that it becomes

$$
C(q)=c_{o}+c_{1} q
$$

The comparative static results become, in general, more ambiguous. However, there are reasonable circumstances in which those results continue to hold.

For the case of constant-returns-to-scale in production, as above, a necessary condition for the existence of an optimal level of output is that

$$
1-(1+r) w-c_{1} F_{o}<0
$$

We will assume that (A-18) holds (and in particular that $c_{1}>0$ ). With the now modified bankruptcy cost function, the second order condition takes the form

$$
-\alpha+\frac{2 c_{o} f}{q(1-F)}\left[\frac{d h}{d q}\right]<0
$$

where $\alpha$ and $d h / d q$ are defined above with $C(q)$ in its present form substituted for $c q$. Since the second term in (A-19) is positive, condition (A-12), while necessary for (A-15) to hold, is no longer sufficient (N.B. with CRTS, the second order condition for the decision problem of the body of the paper is $-\alpha<0$ ).

For an interior maximum at which (A-19) holds the impact of a change in the firm's equity level is described by the equation

$$
\frac{d q}{d a}=\left[\frac{q}{a}\right]\left[\frac{\alpha-\mu}{\alpha-2 \mu}\right]>0
$$

where $\mu \equiv\left(c_{o} f / q\right)(d \bar{u} / d h)(d h / d q)$ and, since the second order condition requires that $\alpha-2 \mu>0, \alpha-\mu>0$. Thus, with constant-returns-to-scale, adding a fixed bankruptcy penalty does not alter the direction of a firm's response to an increase in equity (it remains positive), but 
it does intensify the magnitude of the firm's response (since $(\alpha-\mu) /(\alpha-2 \mu)>1$ ). Similar results hold for output responses to changes in real wages, real interest rates and the price distribution $F$. Therefore, to the extent that constant returns to scale characterize a firm's production technology - either because we are studying scale decisions or because we are concerned with levels of output below capacity over which marginal costs are roughly constant -- inclusion of a fixed bankruptcy cost does not fundamentally alter the implications of the model.

\section{More General Utility Functions}

A final obvious extension of the basic model is to settings in which firms' managers maximize over a horizon which is longer than a single decision period. For analytical purposes, this involves considering an objective function of the form

$$
\max _{q_{t}}\left\{q_{t}-\left(1+r_{t}\right)\left(w_{t} \phi_{t}-a_{t}\right)-c q_{t} F\left(\bar{u}_{t}\right)+E\left[V\left(a_{t+1}\right)\right]\right\}
$$

subject to (A-2), where $E$ is a mathematical expectation, $a_{t+1}$ is the firm's equity level entering period $t+1$ and $V$ is a valuation function of the usual sort. Formally,

$$
a_{t+1}=\tilde{p_{t+1}} \cdot q_{t}-\left(1+\tilde{r_{t+1}}\right)\left(w_{t} \phi_{t}-a_{t}\right)
$$

where $1+r_{t+1}$ is the random real return to lenders. ${ }^{41}$ Thus, (A-21) can be rewritten as

$$
\max _{q_{t}} E\left[a_{t+1}+V\left(a_{t+1}\right)\right]-c q_{t} F\left(\bar{u}_{t}\right)
$$

subject to (A-2) with appropriate $t$ subscripts on the variables.

In examining this decision problem, the case of constant returns to scale is again the easiest starting point. With CRTS,

\footnotetext{
41 This ignores dividends. However, including them would complicate the analysis without altering its implications fundamentally.
} 


$$
q_{t}^{*} \equiv \text { optimal } q_{t} \equiv k_{t} a_{t}
$$

Therefore

$$
h^{*}{ }_{t} \equiv \text { optimal level of } h_{t}=\left(1+r_{t}\right)\left(w_{t}-a_{t} / q_{t}^{*}\right)=\left(1+r_{t}\right)\left(w_{t}-1 / k_{t}\right)
$$

which means that $h^{*}, \bar{u}^{*}$ and $F\left(\bar{u}^{*}{ }_{t}\right)$ are independent of $a_{t}$. Thus, $c q^{*} F\left(\bar{u}_{t}^{*}\right)$ is linear in $a_{t}$ and the valuation function for the multiperiod decision problem is linear in $a_{t}$. With constant returns to scale, therefore, the multiperiod decision problem is qualitatively identical to a single period problem and the extension to multiperiod decision-making is straightforward, involving nothing more than a rescaling of the bankruptcy cost factor $c$.

Unfortunately the same simplicity does not apply to the general case and here only the most general principals can be articulated. The flavor of these is captured best by abandoning the specific formulation of "bankruptcy" constraints since these no longer yield unambiguous results and simply assuming that managers choose output to

$$
\max _{q_{t}} E\left[V\left(a_{t+1}\right)\right]
$$

where $V$ is a general utility function, $a_{t+1}$ is the end of period value of a firm's equity

$$
a_{t+1}=\tilde{p_{t+1}} \cdot q_{t}-\left(1+r_{t}\right)\left(w_{t} \phi\left(q_{t}\right)-a_{t}\right),
$$

and $a_{t+1}$ is now allowed to become negative in order to repay lenders. For this problem it is straightforward to show that (1) risk aversion leads to a reduction in output below what a risk neutral firm would produce and (2), if $V$ exhibits decreasing absolute risk aversion, then greater firm equity levels lead to greater output. Thus, if a multiperiod decision problem generates a valuation function characterized by decreasing absolute risk aversion, then in general we should expect the results of the model (with respect to equity levels and output) to apply without change. 
$-38-$

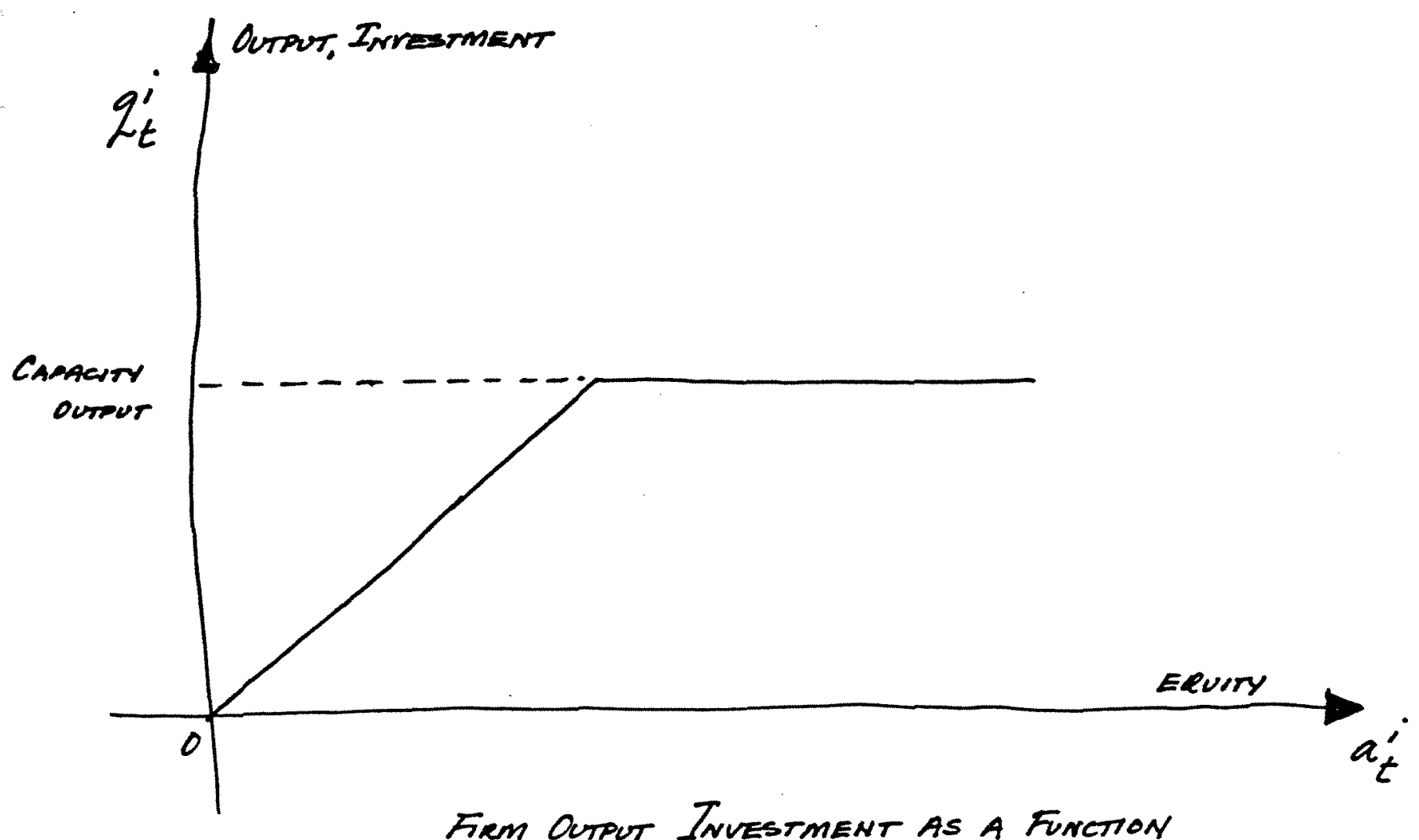

Fiem Ourput, Investment AS A Furetion of FirM EQUITY LEVELS

$\hat{a}_{t+1}$ A Equrry

ReNoD $t+1$ (CRTS, CAPACITY CONSTRAINT)

Foure 1

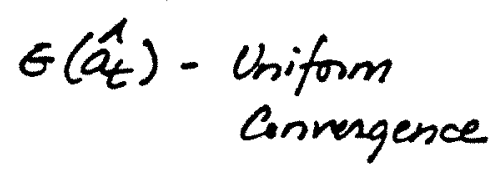$$
G\left(\hat{a}_{t}\right)-\text { Cycles }
$$

STEADY-SOATE DYNAMICS

EQurry Reros $t$

Asgresate Equity Levels in Period tol as a

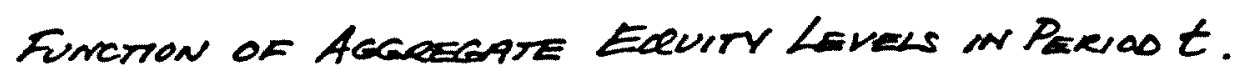

FrGURE $2 A$ 

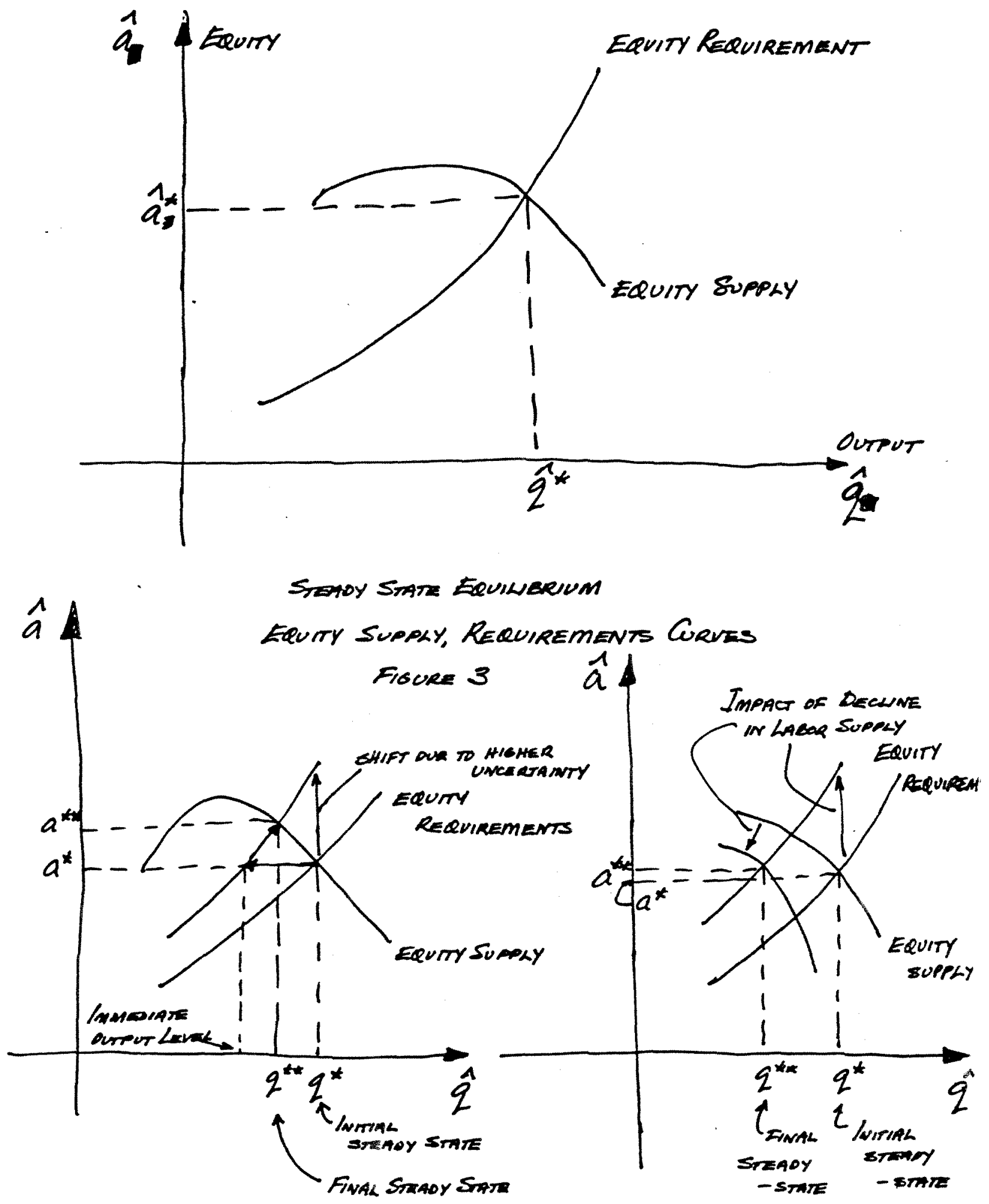

Impact of an Increase in

Ureerninty

FEURE $3 A$

Impact of Decrease

in Laeor Suppay

FEURE $3 B$ 


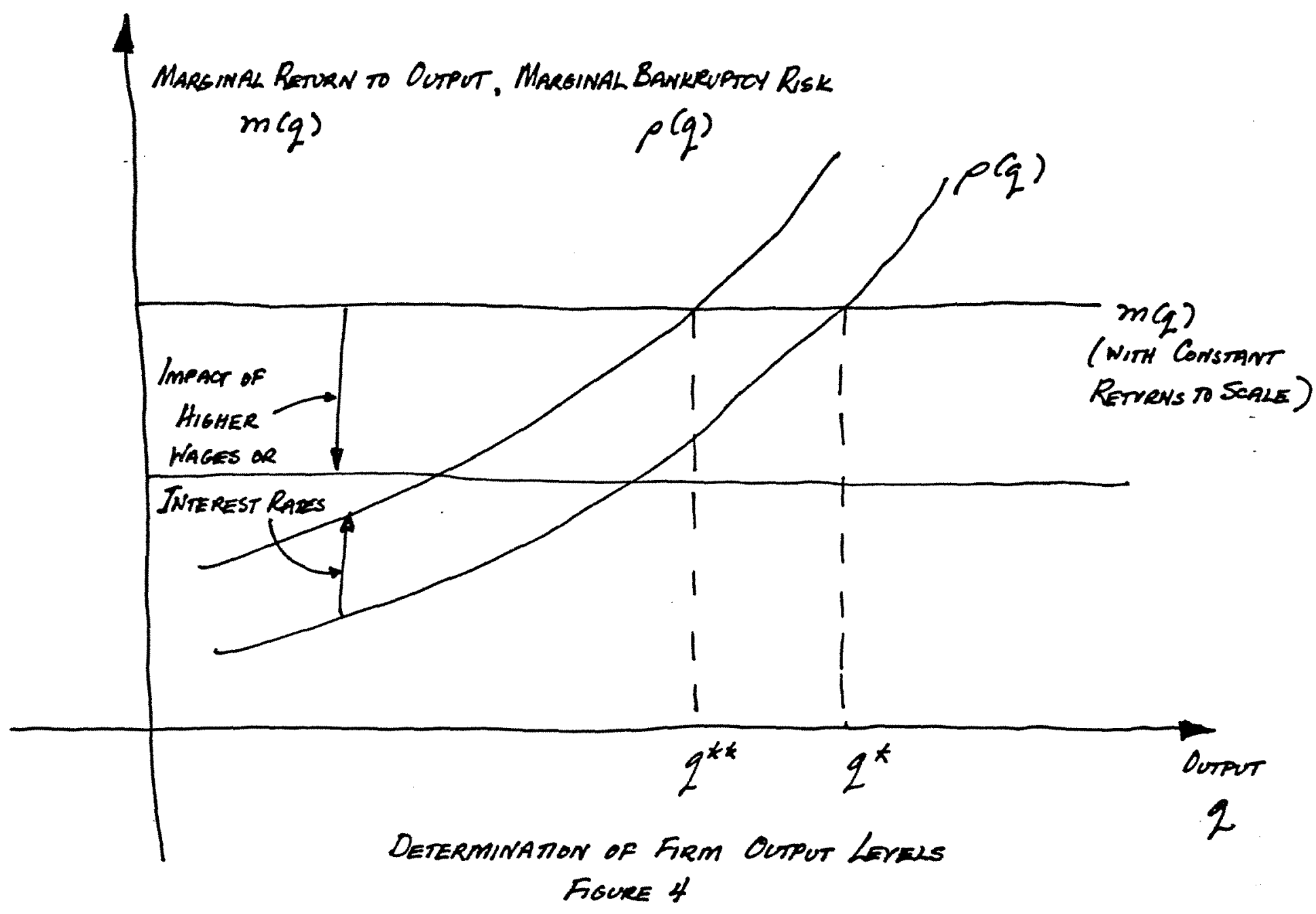




\section{Bibliography}

Akerlof, G. [1970], "The Market for Lemons: Qualitative Uncertainty and the Market Mechanism", Quarterly Journal of Economics, Vol. 84, pp. 288-300.

Akerlof, G. and Stiglitz, J. E. [1969], "Capital, Wages and Structural Unemployment", Economic Journal, Vol. 79, pp. 269-81.

Arrow, K. J. [1970]. Essays in The Theory of Risk Bearing, London, North-Holland.

Asquith, P. and Mullins, D. W. [1983], "Equity Issues and Stock Price Dilution", unpublished paper, Harvard Business School.

Dasgupta, P. and Stiglitz, J. E. [1988], "Learning by Doing, Market Structure and Industrial Trade Policies", Oxford Economic Papers, Vol. 40, pp. 246-268.

Grandmont, J. M. [1985], “'On Endogenous Competitive Business Cycles”, Econometrica, Vol. 53, pp. 995-1046.

Greenwald, B. and Stiglitz, J. E. [1986a], "Externalities in Economies with Imperfect Information and Incomplete Markets", Quarterly Journal of Economics, Vol. 100, pp. 229-264.

Greenwald, B. and Stiglitz, J. E. [1986b], "Information, Fianance Constraints and Business Fluctuations", Proceedings of the Taiwan Conference on Monetary Theory, Taipei, Chung-Hua Institute.

Greenwald, B. and Stiglitz, J. E. [1987], "Imperfect Information, Credit Markets and Unemployment", European Economic Review, Vol. 31, pp. 1-10.

Greenwald, B., Stiglitz, J. E. and Weiss, A. M. [1984], "Informational Imperfections and Macroeconomic Fluctuations", American Economic Review, Papers and Proceedings, Vol. 74, pp. 194-199.

Grossman, S. J. and Stiglitz, J. E. [1976], "Information and Competitive Price Systems", American Economic Review, Papers and Proceedings, Vol. 66, pp. 246-253.

Jensen, M. C. and Meckling, W. H. [1976], "Theory of the Firm: Managerial Behavior, Agency Costs, and Ownership Structure”, Journal of Financial Economics, Vol. 3, pp. 305-60.

Kalecki, M. [1939], Essays in the Theory of Economic Fluctuations, New York, Russell and Russell.

Leland, H. E. and Pyle, D. H. [1977], "Informational Asymmetries, Financial Structure, and Financial Intermediation", Journal of Finance, Vol. 32, pp. 371-87. 
Lucas, R. E. [1988], Marshall Lectures.

Myers, S. C. and Majluf, N. S. [1984], "Corporate Financing and Investment Decisions When Firms Have Information that Investors Do Not', Journal of Financial Economics, Vol. 11, pp. 187-221.

Romer, P. M. [1986], “Capital Accumulation and Increasing Returns”, Ph.D. Thesis, University of Chicago.

Romer, P. M. [1988], "Capital Accumulation in the Theory of Long Run Growth", University of Rochester, mimeo.

Ross, S. A. [1977], "The Determination of Financial Structure: The Incentive Signalling Approach", Bell Journal of Economics, Vol. 8, pp. 23-40.

Stiglitz, J. E. [1972], “Information and Capital Markets”, in C. Cootner and W. Sharpe, eds., Essays in Honor of Paul Cootner, Prentice Hall, NJ.

Stiglitz, J. E. [1985], “Credit Markets and the Control of Capital', Journal of Money, Credit and Banking, Vol. 17, pp. 133-152.

Stiglitz, J. E. and Weiss, A. M. [1981], "Credit Rationing in Markets with Imperfect Information", American Economic Review, Vol. 71, pp. 393-410.

Taggart, R. A. [1983], "Secular Pattems in Financing U.S. Corporations", unpublished paper, Harvard University.

Woodford, M. [1986], “Expectations, Finance and Aggregate Instability”, unpublished paper, Columbia University and New York University. 